NIST Special Publication 1225

\title{
Standard Reference Data Workshop Report
}

\author{
Debra Kaiser \\ Neil Alderoty \\ Richard Cavanagh \\ Barbara Guttman \\ Robert Hanisch \\ Adam Morey \\ Jeanita Pritchett \\ Yuri Ralchenko \\ Stacy Schuur \\ William Wallace
}

This publication is available free of charge from: https://doi.org/10.6028/NIST.SP.1225

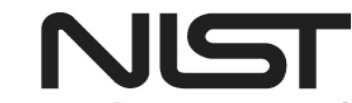

National Institute of Standards and Technology U.S. Department of Commerce 
NIST Special Publication 1225

\title{
Standard Reference Data Workshop Report
}

\author{
Debra Kaiser \\ Robert Hanisch \\ Adam Morey \\ Office of Data and Informatics \\ Material Measurement Laboratory \\ Richard Cavanagh \\ Special Programs Office \\ Laboratory Programs \\ Barbara Guttman \\ Information Technology Laboratory \\ Yuri Ralchenko \\ Physical Measurement Laboratory \\ Jeanita Pritchett \\ Neil Alderoty \\ Stacy Schuur \\ William Wallace \\ Material Measurement Laboratory
}

This publication is available free of charge from:

https://doi.org/10.6028/NIST.SP.1225

June 2018

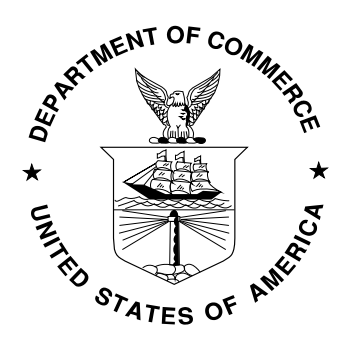

U.S. Department of Commerce Wilbur L. Ross, Jr., Secretary

National Institute of Standards and Technology Walter Copan, NIST Director and Undersecretary of Commerce for Standards and Technology 
Certain commercial entities, equipment, or materials may be identified in this document in order to describe an experimental procedure or concept adequately. Such identification is not intended to imply recommendation or endorsement by the National Institute of Standards and Technology, nor is it intended to imply that the entities, materials, or equipment are necessarily the best available for the purpose.

National Institute of Standards and Technology Special Publication 1225

Natl. Inst. Stand. Technol. Spec. Publ. 1225, 37 pages (June 2018)

CODEN: NSPUE2

This publication is available free of charge from:

https://doi.org/10.6028/NIST.SP.1225 


\title{
Foreword
}

The Material Measurement Laboratory (MML) has responsibility for the NIST-wide Standard Reference Data (SRD) Program, and the Office of Data and Informatics (ODI) in MML leads, oversees, and manages the SRD Program as one of its many responsibilities. SRDs are a vital component of NIST's standards mission and providing critically evaluated data has contributed substantially to NIST's reputation as a leader in the international standards community.

\begin{abstract}
On October 17, 2017, the ODI sponsored a day-long Standard Reference Data Workshop. More than 120 NIST staff members and associates from four NIST laboratories and three offices registered for this workshop. The workshop format consisted of presentations, panel sessions, and breakout sessions. Topics included the current state of the SRD Program, technical activities, use metrics and impacts, and technology, business, and SRD life cycle considerations. This report summarizes the presentations and discussions on the above topics, and concludes with recommendations from the workshop attendees.
\end{abstract}

\section{Key words}

Standard Reference Data; SRD; Office of Data and Informatics 
Table of Contents

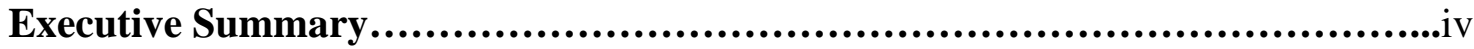

1. Workshop Introduction....................................................1

1.1. Objectives........................................................ 1

1.2. Format.............................................................. 1

1.3. Organizing Committee.................................................... 1

1.4. Registrants......................................................... 1

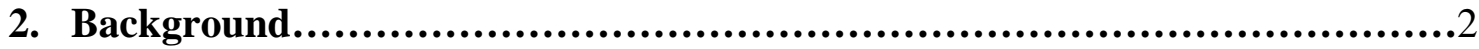

2.1. Historical perspective on NBS/NIST data products....................... 2

2.2. SRD Act and Update................................................ 2

2.3. SRD modernization program.......................................... 3

3. Current State of the Program.................................................... 3

3.1. Fee-based SRD products.......................................... 3

3.2. Free SRD web interfaces............................................4

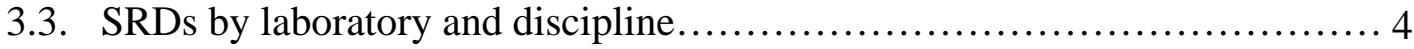

4. Technical Activities.............................................................4

4.1. Critical evaluation.................................................. 4

4.2. Internal review of free data products.................................. 5

4.3. SRD as part of the broader data community .............................. 6

4.4. SRD enhancement/development projects............................... 7

4.5. SRD and the NIST Quality System.................................. 7

5. Technology Considerations............................................... 7

5.1. Data acquisition and management.................................... 7

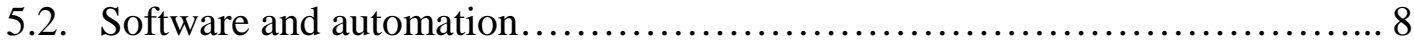

5.3. IT resources....................................................... 8

5.4. Disruption from technology shifts.................................. 8

6. Use Metrics................................................................. 8

6.1. Existing metrics................................................... 8

6.2. New metrics.................................................... 9

6.3. Impacts......................................................... 9

7. SRD Life Cycle Considerations............................................... 10

7.1. Needs assessment stage.......................................... 10

7.2. Development stage..................................................... 10

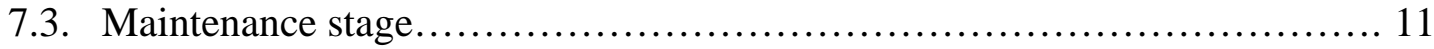

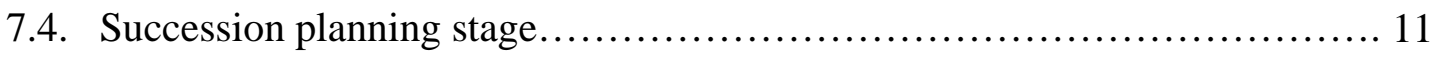

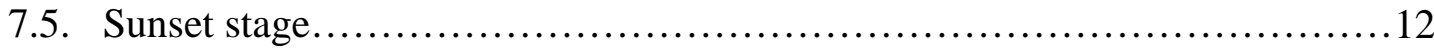


8. Business Considerations......................................................... 12

8.1. Copyright.......................................................

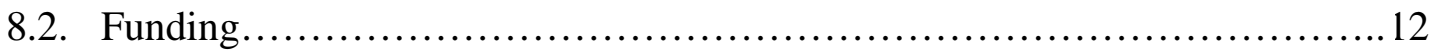

8.3. Dissemination and distribution..................................... 13

8.4. Marketing......................................................... 13

9. Recommendations................................................................. 14

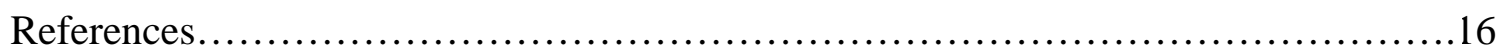

Appendix A. Workshop Agenda................................................. 17

Appendix B. Workshop Registrants..........................................20

\section{List of Tables}

Table 1. Sales of fee-based SRDs............................................. 4

\section{List of Figures}

Fig. 1. Distribution of registrants by NIST laboratory............................. 2

Fig. 2. Free data products by discipline......................................4

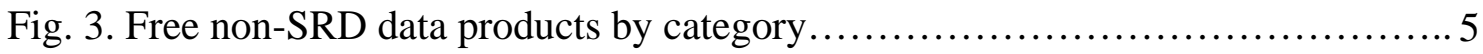

Fig. 4. Latest date of new content for all free data products........................ 6

Fig. 5. NIST data taxonomy pyramid...................................... 6 


\section{Executive Summary}

The National Institute of Standards and Technology (NIST), formerly the National Bureau of Standards (NBS), has, for over a century, been a provider of high quality scientific data in support of the U.S. and international research and industrial communities. NIST's Standard Reference Data (SRD) program is highly regarded, and the NIST "brand” has come to represent the most thorough characterization and the highest level of reliability of data products. While many NIST SRD products remain as unparalleled exemplars, undergoing continuous extensions and improvements, others have not been updated and are in danger of becoming obsolete. A recent SRD Technical Review [1] also identified that roughly 1/3 of the free, web-based SRD products do not meet the high level of standards for critical evaluation associated with the SRD label.

Production and maintenance of SRD are long-term efforts that require the expertise and experience of senior NIST research staff. NIST's reputation for the provision of SRD-a reputation earned over decades of service-is a precious commodity that should not be allowed to suffer owing to neglect. The importance of quality data for evidence-based decision making and increasing the reliability and reproducibility of research [2] is being recognized throughout government, industry, and society.

As was clear from the SRD Workshop, many at NIST share these convictions about the importance and relevance of the SRD program. NIST needs to find a way to better support SRD development, curation, maintenance, and distribution, taking into consideration practical matters such as succession planning as experienced staff retire. Continuing with the status quo is likely to lead to decreasing relevance of the portfolio and potential damage to NIST's reputation for the highest quality of, and independence in, data evaluation. 


\section{Workshop Introduction}

The Office of Data and Informatics (ODI) in the NIST Material Measurement Laboratory sponsored a day-long Standard Reference Data Workshop, held on October 17, 2017 at the NIST Gaithersburg campus. This comprehensive report represents a summary of the Workshop, highlighting input from NIST staff members and associates on a variety of SRD-related topics.

\subsection{Objectives}

The objectives of this internal Workshop were four-fold:

(a) Review the history of the Standard Reference Data (SRD ${ }^{1}$ ) Program

(b) Examine the Program's current state

(c) Discuss options for the future of the Program, including expansion of the portfolio considering the redefinition of SRD as described below

(d) Gather information for use in a report that will inform priority assessments and resource allocation decisions in the coming years

\subsection{Format}

The format of the workshop consisted of presentations, panel sessions, and breakout sessions. An agenda is presented in Appendix A. There were 12 presentations covering the history of data programs at NBS/NIST, SRD legislation, plans for SRD modernization, SRD enhancement/development projects (short "lightning" talks), a technical review of the current SRDs, and the new NIST Quality System. There were two panel sessions and two breakout sessions; the topics for the panel members and attendees at the breakout sessions are also presented in Appendix A. These questions were designed to address topics concerning technical activities, technology developments, metrics and impacts, life cycle stages, and business considerations.

\subsection{Organizing Committee}

Robert Hanisch, Director, ODI, Material Measurement Laboratory (MML)

Neil Alderoty, Executive Director, MML

Richard Cavanagh, Director, Special Programs Office (SPO), Laboratory Programs (LP)

Barbara Guttman, Group Leader, Information Technology Laboratory (ITL)

Adam Morey, Group Leader, MML

Jeanita Pritchett, Scientific Advisor, MML

Yuri Ralchenko, Group Leader, Physical Measurement Laboratory (PML)

Stacy Schuur, Scientific Advisor, MML

William Wallace, Group Leader, MML

\subsection{Registrants}

There were 123 registrants for the workshop, primarily from four NIST laboratories - the Engineering Laboratory (EL), ITL, MML, and PML. The distribution of registrants by Laboratory is shown in Fig. 1. Two-thirds of the registrants were from MML, which is not unexpected as the ODI is part of MML. There were also registrants from the Management Resources (MR) Information Services Office (5), LP (2), and the NIST Directors Office (1).

\footnotetext{
${ }^{1}$ The acronym SRD is also used for Standard Reference Database.
} 
The individuals that registered for the workshop and their NIST affiliations are presented in Appendix B. The diversity of backgrounds, experiences, and opinions of the participants were critical to the success of the workshop.

\section{Background}

This section of the report provides information on the history of data efforts at NIST, legislative actions concerning SRD, and ongoing modernization efforts of the SRD Program via presentations by Hratch Semerjian and Robert Hanisch.

\subsection{Historical perspective on NBS/NIST data products}

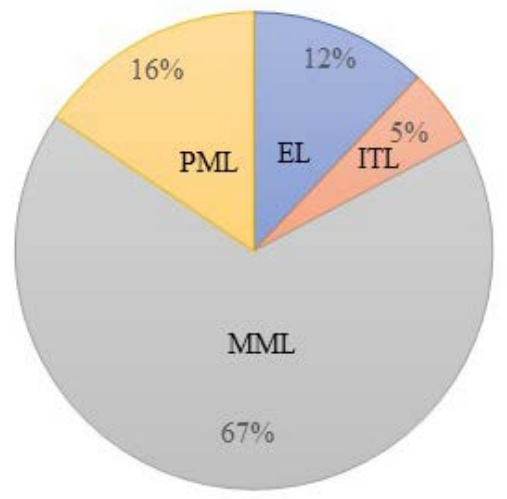

Fig. 1. Distribution of registrants by NIST laboratory.

Hratch Semerjian presented a comprehensive lecture on the rich history of data at NBS/NIST, dating to 1909 with a concerted effort on the properties of refrigerants. In the next 15 years, NIST became renowned for international critical tables, phase equilibria, chemical thermodynamic properties, and atomic spectroscopy data, and for evaluation of the quality of such data. In 1963, NBS established the Office of Standard Reference Data to develop a National Standard Reference Data System [3]. The emphasis of this system was the production of compilations of critically evaluated data; several of the data compilations were developed in partnership with other organizations. As described below, the Standard Reference Data Program was established in 1968 to "ensure that reliable reference data are easily accessible by scientists, engineers and the general public.” Between 1930 and 1980, major data programs were initiated, including the Handbook of Mathematical Functions and the Mass Spectral Library.

\subsection{SRD Act and Update}

In 1968, Congress passed the Standard Reference Data Act [4], a law that authorized and directed the Secretary of the Department of Commerce to provide or arrange for the collection, compilation, critical evaluation, publication, and dissemination of standard reference data. The Act defined SRD as "quantitative information, related to a measurable physical or chemical property of a substance or system of substances of known composition and structure, which is critically evaluated as to its reliability.” Appropriations to carry out the SRD Act were authorized in 1969 [5], and funds were provided in fiscal years 1970 and 1971 to formalize the SRD Program, a hallmark of NBS's and now NIST's measurement services.

In 2015-2016, the ODI Director co-led an effort to expand the scope of SRD. This effort resulted in Section 108, Standard Reference Data Act Update, in Public Law No. 114-329, American Innovation and Competitiveness Act [6]. In this 2017 Update, the term SRD means data that are-

a. either-

i. quantitative information related to a measurable physical, or chemical, or biological property of a substance or system of substances of known composition and structure;

ii. measurable characteristics of a physical artifact or artifacts;

iii. engineering properties or performance characteristics of a system; or

iv. one or more digital data objects that serve- 
(a) to calibrate or characterize the performance of a detection or measurement system; or

(b) to interpolate or extrapolate, or both, data described in (i)-(iii); and

b. that is critically evaluated as to its reliability under section 290b of this title.

Digital data objects may include fingerprints, personal identity verification cards, videos, models, and software.

\subsection{SRD modernization program}

In late 2015, the ODI initiated a process to evaluate the SRD Program. A Program Review Committee was convened to consider modernization of the SRD Program, including web interface redesign, application programming interfaces (APIs), and technical content.

Discussions focused on two technical issues: (1) the factors considered in the assignment of SRD numbers to data products over the past two decades are unclear; and (2) many SRDs are quite old - $48 \%$ of the free SRDs have not been updated in the past decade. The committee confirmed the importance of the SRD Program and recommended that a comprehensive technical review be performed to address the following issues:

1. Are there SRDs that are incorrectly categorized or retained?

a. Obsolescence of content or function

b. Inadequate evaluation

c. Not compliant with the SRD Act

2. Are there Special Databases that should be SRDs?

Following the recommendation of the committee, the ODI initiated a technical review of the SRD Program. There are four goals of the review:

1. Assure that NIST is delivering the highest quality products and maintaining the NIST SRD "brand" in compliance with the SRD Act Update;

2. Identify SRDs of great use and impact that would benefit from updates;

3. Discern potential gaps in the SRD program that NIST could or should remedy; and

4. Understand the technical impact that the SRD program has had for industry, other government agencies, and the academic research community.

Note that the SRD label allows NIST, through the Secretary of Commerce, to hold copyright and, where appropriate, to charge fees for the use of SRD to recover costs of production and distribution.

\section{Current State of the SRD Program}

This section of the report describes the various types of SRD products and provides distributions for FY 2017, as reported by Robert Hanisch and Debra Kaiser.

\subsection{Fee-based SRD products}

There are 41 fee-based SRD products, see https://www.nist.gov/srd. Table 1 shows the six mechanisms by which these SRDs are sold and the number by mechanism in FY 2017. The total income from these SRDs in FY 2017 was $\$ 8.29$ M; leading the sales was SRD 1A, NIST/EPA/NIH Mass Spectral Library, at \$6.8 M. 


\subsection{Free $S R D$ web interfaces}

There are 75 free SRDs which are available via web interfaces. For each free data product, the number of users may be assessed by Google Analytics; however, this is a tedious and timeintensive undertaking. The most popular free SRD is the Chemistry WebBook, which had 2.9M users in FY 2017.

\subsection{SRDs by laboratory and discipline}

All fee-based SRDs are produced by MML. Of the 75 free SRDs, sometimes referred to herein as "data products," the distribution by Laboratory is: PML-37; MML-36; ITL-1; and EL-1. The number distribution of free data products by discipline is shown in Fig. 2 .

\section{Technical Activities}

This section of the report is largely based on workshop presentations and includes a summary of a panel session on critically evaluated data.

\subsection{Critical evaluation}

There are various methods to evaluate data; this section focuses on critical evaluation. What is meant by critically evaluated data is not addressed in the 1968 SRD Act, the 2017 SRD Act Update, nor in numerous NBS Bulletins on this topic. Prior to the workshop, the ODI developed the following definition of and criteria for critical evaluation based on a seminal publication on critical evaluation of data [7] and on input from SRD researchers.

"Critically evaluated data are assessed by experts and are trustworthy such that people can use the data with confidence and base significant decisions on the data.” The SRD Act Update of 2017 covers numerical data and digital data objects, e.g., images, software, videos. Criteria for critical evaluation of these two classes of data are given below.

\section{Numerical data:}

- Assuring the integrity of the data, e.g., by provision of uncertainty determinations and use of standards;

- Checking the reasonableness of the data, e.g., by consistency with physical principles and comparison of data obtained by independent methods; and

- Assessing the usability of the data, e.g., by inclusion of metadata and well-documented measurement procedures

\section{Digital data objects:}

- Assuring the object is based on physical principles, fundamental science, and/or widely accepted standard operating procedures for data collection; and 
- Checking for evidence that

- The object has been tested, and/or

- Calculated and experimental data have been quantitatively compared

The definition and criteria were presented by Debra Kaiser and were displayed during a subsequent panel session. Below are responses from the panel members to the question "How would you define critical evaluation?”

- Expert judgement, e.g., hands-on knowledge of a field by one or more individuals

- Access to and use of all relevant publications

- Critical revisions to published data

- Substantial amount of modeling

- Substantial amount of subjective evaluation

- Application of a consistency analysis with other data that were reviewed

- Uncertainty determination

- Understanding how data were measured

- Understanding how data should behave

- Documented procedures for review of data

- Availability of a comprehensive body of data

- Least-squares analysis (for CODATA fundamental physical constants)

There was wide-ranging input on methods used in critical evaluation, all of which are consistent with the ODI-developed criteria presented above.

\subsection{Internal review of free data products}

An internal technical review of the free data products was presented by Debra Kaiser. Results of the review led to the conclusion that 49 (65\%) of the free data products are consistent with the 2017 SRD Act Update and the criteria for critical evaluation (see section 4.1). These 49 data products will retain the SRD label. The remaining 26 (35\%) data products will be reclassified into one or more of the following six categories that better describe the content of these data products:

- Bibliographic Collection (BC)

- Information Resource (IR)

- Portal (P) to other data products and SRDs

- Search Engine (SE) for databases that are not critically evaluated or hosted or curated by NIST

- Software (SW)

- Data Compilation (DC): data do not meet the critical evaluation criteria

The number distribution of these 26 data products is shown in Fig. 3.

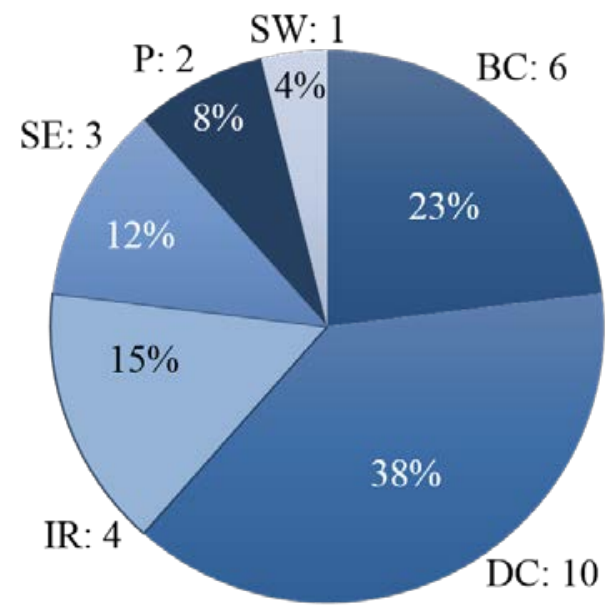

Fig. 3. Free non-SRD data products by category. 
As part of the internal review, the latest date of new content for each data product was determined and analyzed. The dates ranged from 1983 to 2017; the number of data products by decade is presented in Fig. 4 . About $50 \%$ of the data products have not had content updates in the past 10 years. There are several reasons for this, including:

- The original technical contact left NIST or was assigned to a different project;

- The topic was no longer a priority for the NIST division or laboratory;

- The data are essentially invariant due to the fundamental nature of the content; or

- The data are for calibration purposes

When the NIST data website

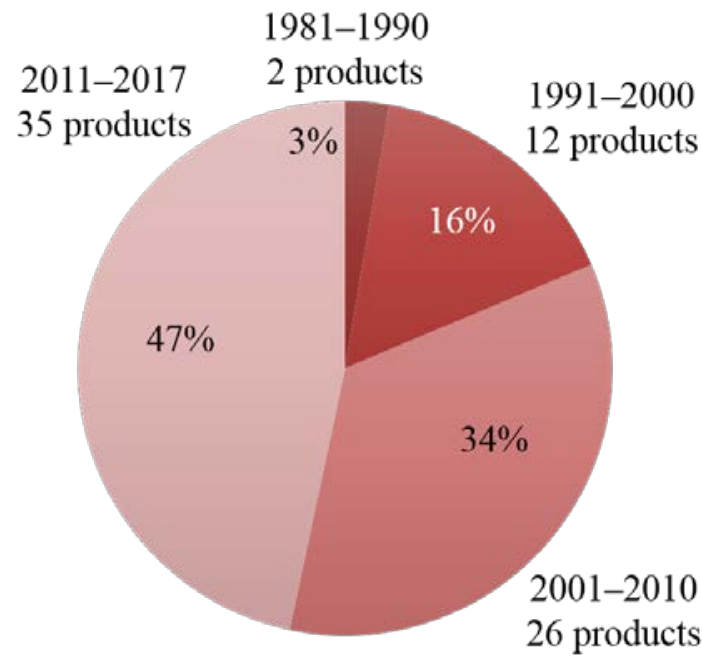

The categories of data in the 2017 NIST Data Taxonomy pyramid are shown in Fig. 5 . The SRD label carries a strong imprimatur. Other types of data sets may be considered for SRD status provided the data can be brought into compliance with the definition and criteria for critical evaluation presented in section 4.1. The "readiness" level of various data sets for advancement to SRD can be considered as follows.

1. NIST Special Databases: These digital data objects are tested extensively, and, based on the 2017 SRD Act Update, are eligible for SRD status.

2. Standard reference materials (SRMs): The accompanying data in an SRM Certificate of Analysis are subjected to rigorous statistical analysis to identify all sources of error in the measured (certified) property values. Particularly in the case where an SRM artifact is an unaltered commercial source of material, the data may be assigned SRD status.

3. Reference materials (RMs): The measured (reference) property values in a RM Report of Investigation undergo statistical evaluation. If a RM artifact is an unaltered commercial source of material, it may be possible, with additional measurements and analyses, to classify the data as SRD.

4. Data Compilations: These data sets, previously assigned as SRDs, have been reclassified as described in section 4.2. Critical evaluation could elevate these data sets to SRD status.

5. Published data: Published data do not typically meet the stringent evaluation criteria for $\mathrm{SRD}$; however, with additional effort, it may be possible to generate SRD from published data. 
6. SRD Enhancement/Development Projects: The NIST Associate Director for Laboratory Programs funded seven SRD enhancement/development projects in FY 2016, the results of which are now coming to fruition. As these projects were specifically intended to either improve existing SRDs or develop new ones, the latter are clear candidates for SRD status. It might be possible to support similar SRD development efforts in the future.

\subsection{SRD enhancement/development projects}

The seven SRD enhancement/development projects were presented as short lightning talks. The topics of these projects and the names of the presenters are shown in Appendix A. Significant progress has been made in achieving the goals set forth in most of these innovative and challenging projects.

\subsection{SRD and the NIST Quality System}

Sally Bruce reported on the Quality System for NIST's measurement services, highlighting SRD. The NIST Quality System underpins international recognition of the U.S. national standards, and NIST's measurements, data sets, and measurement results. The International Organization of Standardization document ISO/TS 8000 on Data Quality specifies the characteristics of data quality as provenance, accuracy, and completeness. As stated in the current NIST Quality Manual (QM-1), an SRD product requires that techniques, methods, and procedures are documented by a Division, and Division Chiefs must ensure that data evaluation is documented and data quality addresses the characteristics specified above. Currently, the accompanying information for an SRD is minimal but uniform. The QM-1 will be updated based on the definition of evaluated data and the criteria for critical evaluation as put forth in this workshop.

\section{Technology Considerations}

This section includes input from workshop attendees at three breakout session topics: "How can we improve data gathering (internal and external sources) in an efficient manner?”, "Best practices for technology shifts", and "Best practices for life cycle planning." Technology advances and the timely implementation of such advances are essential to engage with the modern data consumer while remaining compliant with NIST policies. SRD require continuous improvement to enable new technologies to enhance both data collection and the user experience.

\subsection{Data acquisition and management}

For current SRD products, data experts typically gather data from the published literature and other reliable sources and/or generate data themselves, critically evaluate the data, and compile the data in a useable format. There are technology solutions for data acquisition and management that may accelerate and expand updates to existing SRDs, as well as facilitate the development of new SRDs. It is essential that such solutions are cost-effective and efficient. One interesting possibility for enhancing the availability of data is community-based data gathering, whereby the external community submits data to NIST for validation. This approach requires a well-designed work-flow, and automation of data gathering and processing is advantageous. It is desirable that the data are provided to NIST in standard data formats with specific requirements that are established via coordination and collaboration with all stakeholders; e.g., major international journals in the field, international data organizations and committees, instrument manufacturers, industry, other government agencies, academia, and national metrology institutes. This is a huge undertaking and there are but a handful of fields where this has been successfully accomplished. 
It is possible that some of the data gathered in this manner will be of SRD quality. Another data source is electronic data that is required by some publishers or organizations such as the Protein Data Bank. There are opportunities to learn how Google and Amazon gather, handle, and use data. Regardless of the data source, implementing new methods for data acquisition and management will require substantial investments.

\subsection{Software and automation}

The NIST SRD Program should move away from removable media such as CDs and DVDs and focus on downloads and electronic transactions. The trend toward electronic laboratory notebooks should facilitate the development of databases that may ultimately become SRDs. The use of no cost software is preferable to expensive software; however, open source code may limit collaborations with industry that prefer the use of proprietary software. Such software should be avoided unless a useful export mechanism exists. The ability to export data in various formats provides desired flexibility. There should be an emphasis on APIs, with web graphical user interfaces (GUIs) being secondary; GUIs are technically complex and tutorials must be provided for their use. There should be increased use of Git submodules in a cloud repository, and machine learning to assist with inflow and data quality evaluation.

\subsection{IT resources}

Complex SRD web applications with multiple internal databases and medium-to-high performance needs require substantial annual investment in the form of fees to the NIST Office of Information Systems Management and labor costs for IT compliance from the group or division responsible for that SRD. Access to shared resources is desirable, as is continual and bidirectional engagement between scientists and IT specialists. Providing centralized technical and programming support and dedicated IT and website developers helps to make products available and user-friendly. There is a concern that IT security is at odds with technology resilience and interoperability.

\subsection{Disruption from technology shifts}

The workshop participants identified several approaches to minimize disruption in an SRD product from technology shifts. It is important to develop practices to assure clear, comprehensive documentation, version control, continuous integration, test-driven development, and persistent identification of SRDs. In designing an SRD, a plan should be developed to address migration or evolution of the product, regular review practices, and new technology. Training in new technology areas and their applicability to an SRD are key to evolving the product.

\section{Use Metrics and Impacts}

The latter two topics in this section of the report include input from the breakout session topic "How to measure the impact of an SRD?" SRD product metrics justify investment and provide attribution for SRD researchers. Metrics such as web site statistics are easy to collect; economic impact metrics and consistent citation metrics are more difficult.

\subsection{Existing metrics}

Several different metrics have been employed to demonstrate usage of SRDs. These include sales figures and numbers of downloads and citations. In 2015, the NIST Information Services Office (library) conducted a limited citation analysis of 88 SRDs using the Web of Science and Google Analytics. SRDs cited in US and international patents were also investigated. 


\subsection{New metrics}

The collection of effective metrics is likely to require engaging with SRD users in new and creative ways. Below are some new metrics proposed by the workshop participants:

- Usage of data in publications

- Participation in discussion forums (NIST does not have a public discussion forum for data products.)

- Data product user registration

- Anecdotal evidence, testimonials, and user feedback

- Direct communication with industry to learn about the monetary impact of using an SRD

- Customer queries, e.g., registered users

- Usage agreements with consumers, i.e., encourage users of NIST SRD to describe use cases and resulting outcomes to NIST. (Note: Such agreements are labor-intensive to create, manage, and enforce.)

- Number of SRDs used to support legal cases and used in patents

- Number of mentions on twitter, blogs, other social media, news, web pages, and so forth

- Number of products incorporated into instruments and products (this may hide the impact)

- External requests for updates and revisions to SRDs

\subsection{Impacts}

Linking metrics to actual impact is typically a difficult task. A study on the impact of SRDs was conducted by the Department of Commerce Data Service in 2016. The study focused on three means to gauge impact: (1) Google Analytics; (2) SRD private sector business profiles; and (3) interviews with companies making extensive use of NIST SRDs. The Google Analytics results were inconclusive as most user sites hide the IP domain or show only their IP service provider. Larger businesses are more likely to use SRDs, but there was no evidence that companies have greater revenue because they use SRDs. Telephone interviews with 20 major SRD customers were problematic due to difficulties in establishing contact with an appropriate technical individual who could provide at least anecdotal evidence on the impact of using an SRD. A specific NIST impact study on SRD 69, Chemistry WebBook, revealed that, in 2016, the website had 1,720 citations by URL (from Google Scholar), and 2.66 M users and 4.46 M sessions (from Google Analytics).

The workshop attendees suggested ways to measure impact, some of which are linked to the metrics listed above.

- Generate citation history and conduct citation analyses: who is citing the SRDs and how are they using them?

- Standardize the citation language

- Create reusable, smart queries that search, e.g., data product name, current and previous technical contacts

- Ascertain how SRD are used to support legal cases and used in patents

- Utilize Web Analytics (Google Analytics expertise from Public Affairs Office is required) and API logs

- Analyze the distribution of the number of downloads/purchases 
- Commission economic impact studies (cautioning, though, that these studies are difficult, expensive, and not always accurate)

- Create on-demand citation and web analytic reports for the entire SRD catalog to capture usage trends

- Query vendors whose instruments incorporate SRDs regarding customer impact

\section{SRD Life Cycle Considerations}

Life cycle aspects of SRDs were touched on throughout the workshop; attendees' responses to the following three breakout session topics formed the basis for this section of the report.

1. "Beginning a dataset/SRD"

2. "Curation and maintenance of a data project over time"

3. "Best practices for life cycle planning: succession planning; funding; and sunsetting" These topics naturally lead to five life cycle stages - needs assessment, development, maintenance, succession planning, and sunsetting.

\subsection{Needs assessment stage}

The workshop participants' input on needs assessment centered on stakeholder engagement. A NIST staff member can identify a data gap or socialize an idea for a new SRD through attendance and networking at scientific meetings and workshops and discussions with other Federal agencies or industry. NIST may also host workshops to identify customer needs. Ideas can also be formulated by reviewing scientific literature and searching public forums. On the other hand, individual or communities of stakeholders may approach NIST staff members to discuss data needs. There are also inquiries via electronic communication mechanisms.

Needs for new SRDs are most likely to arise from burgeoning fields such as biology and from new technologies and commercial product areas. Internally, new NIST strategic directions may drive the need for evaluated data and additional staff members with requisite expertise may be required to address advanced science and technology needs. The markets for SRDs are determined by several factors and may range from broadly applicable SRDs to ones with a specific customer base such as a Federal agency. Market research is a critical aspect of assessing needs. The NIST Information Services Office (library) has resources to assist with market research. Development of a best practices guide for performing market analysis was suggested.

\subsection{Development stage}

Once there is a clear need, identified customers, and a strong market case for a new SRD, the development stage may proceed. The steps in developing an SRD are as follows:

1. Define a scope

2. Determine if the SRD will be free or fee-based: see section 8.2

3. Secure funding from: division, central source, competitive funding opportunity (such as the ODI's SRD enhancement/development projects), other Federal agencies

4. Establish the form of the data: numerical, digital data object

5. Curate the data: see below

6. Evaluate the data: see section 4.1

7. Establish the document format: e.g., methods and procedures, data presentation

8. Complete the document and publish as an SRD (free SRDs), or make available for sale (fee-based SRDs) 
Data curation is a large part of the development process; one breakout session topic focused largely on curation. The workshop attendees described curation as making data useable, an act of examination and evaluation, and adaptive data management. For data curated electronically, the processes are described as follows:

1. Collection: systematic approach to gathering data and associated metadata from a variety of sources and/or generating data and associated metadata.

2. Ingestion: process of importing data for immediate use or storage in a database.

3. Structuring: a specialized format for organizing and storing data to suit a specific purpose so that it can be accessed and worked with in appropriate ways.

4. Annotating: metadata-underlying information about the data

5. Conceptualizing: consistent, logical, and extensible representation of one or more datasets.

6. Scrubbing: process of amending or removing data in a database that is incorrect, incomplete, improperly formatted, or duplicated.

7. Archiving: process of moving data that is no longer actively used to a separate storage system for long-term retention.

8. Disposal

These processes are also relevant for data that are collected manually and entered into a database. Both electronic and manual processes have been used for NIST's current SRDs.

The workshop attendees also noted that curation involves decisions based on judgment, which requires knowledge of measurement methods, current state of the field, and stakeholder needs. Curation involves documenting formats and explicit criteria for evaluation, tracking versions, and documenting and tracking all decisions that affect the data.

\subsection{Maintenance stage}

Sustainable maintenance, also known as updating, is key to the long-term success of an SRD. The workshop attendees' comments can be summarized in the three areas below:

1. Planning: Maintenance should be included in the initial plan for an SRD. Issues to be considered include an extensible design to meet future demands for new data; sustainable resources, including funding and personnel; and the ability to maintain the required infrastructure, both experimental and computational.

2. Needs assessment: Determining the need for updates depends on customer requests for new data, stakeholder engagement, and how rapidly the fields that require specific data are changing.

3. Technology: SRD researchers need to continually educate themselves in the most efficient ways to manage data and use relevant IT technology.

\subsection{Succession planning stage}

To keep an SRD current, a succession plan involving management and SRD researchers must be developed. Successors to an SRD principal researcher may be new hires or other, typically more junior, NIST staff members. Successors need to be trained and mentored, and well-documented procedures must be in place for them to follow. To facilitate the transition of an SRD, the SRD principal researcher may opt for phased retirement, or be re-employed as an annuitant. It is imperative that management make a programmatic and funding commitment to sustain an SRD and to support a successor. 


\subsection{Sunset stage}

Sunset, the final stage in the life cycle of an SRD, can occur for several reasons:

1. The SRD principal researcher is no longer available to lead the effort;

2. Customer need for the data has diminished or ended, as indicated by dwindling sales or citations;

3. Lack of funding; and/or

4. Lack of a succession plan.

The options for an SRD at the sunset stage are as follows:

1. Archive to long-term storage;

2. Retain on the NIST website with the date of latest new content prominently displayed (for free SRDs); or

3. Transfer the SRD to another organization.

\section{Business Considerations}

The material presented below is based on numerous topics covered in the two panel sessions and one of the two breakout sessions.

\subsection{Copyright}

Per the 1968 SRD Act, "the Secretary [of Commerce] may secure copyright and renewal thereof on behalf of the United States as author or proprietor in all or any part of any standard reference data he [or she] prepares or makes available under this Act, and may authorize the reproduction and publication thereof by others." Copyright issues were discussed at the panel session on "When data becomes an SRD." A summary of the discussion is as follows. There are three purposes of the SRD copyright - to ensure the integrity of a database, to declare that a database is a NIST product, and to protect and sell a database. Scientific data are not subject to copyright protection. What can be copyrighted is the embodiment, layout, arrangement, and metadata in a database. Collectively, these provide great value to users of a database. An open question is what it means to copyright something NIST does not fully own. It was noted that copyright is used differently for each SRD product. In some sense, NIST can control what its customers are using.

An issue was raised about how CODATA - the Committee on Data of the International Council for Science-handles copyright. CODATA is not concerned with copyright issues and does not copyright its data. However, CODATA does copyright its publications. It was noted that databases are more easily copyrighted internationally.

\subsection{Funding}

Funding was discussed throughout the workshop in the panel and breakout sessions, and has been mentioned in other sections of this report. Funding is a ubiquitous challenge for SRD, particularly in the development, maintenance, and succession planning life cycle stages, as detailed above. Stable and sustainable funding and associated long-term management commitment were called out frequently as being essential to a successful SRD. Cost leveraging, mentioned briefly in the context of sharing booths at trade shows with the Office of Reference Materials, is a concept that should be explored.

Funding discussions centered on two themes: existing and potential sources of funding; and free vs. fee-based SRDs. 
The following sources of funding were identified:

1. STRS Divisional support, with the advantage of assuring that technical data efforts are affiliated with the appropriate Division.

2. STRS centralized support, whereby NIST provides funding to the ODI for distribution to SRD researchers. It was mentioned that SRD could be a line item in the NIST budget.

3. STRS from the Associate Director for Laboratory Programs, which provided funding for seven SRD enhancement/development projects in 2016. Note that this funding was shortterm and does not support a long-term commitment.

4. Other agencies and industry, that primarily provide funding to start SRD projects

5. Sales of fee-based SRDs

6. Centralized support, specifically for IT needs

There are 41 fee-based and 49 free SRD products (per the internal technical review, section 4.2). One of the panels discussed the issue of free vs. fee-based SRDs, and how to price an SRD. One panel member noted that if NIST considers the data to be "safe" (i.e., there are no known risks associated with use or misinterpretation of the data), then the data should be open and free. Another factor in support of free SRDs is that NIST should not be competing with industry that may be generating similar data. Several panel members were associated with fee-based SRDs. It was noted that fee-based SRDs are supposed to operate on a cost recovery basis, which is unrealistic as selling prices to cover all costs would be exorbitant. Pricing an SRD is a difficult process, one where researchers need assistance. Pricing depends on how the product is soldpaid downloads, e-commerce transactions, active distributor agreements, active site licenses, units sold via distributors, and units shipped (DVDs and CDs). For example, for distributor sales, which are typically coupled with instrument vendors, more data can support greater prices or generate greater sales. In contrast, for direct sales, one panel member noted that the focus is on niche systems that lower SRD production costs and enable users to be more specific in what they purchase. The result for any pricing model is that a complex marketing scheme with interacting systems is created, resulting in the need to predict what future SRD products users require and what they are willing to pay for such products.

\subsection{Dissemination and distribution}

This section and the following section on marketing are based on comments from the breakout topic "Best practices for dissemination, distribution, and marketing of SRD.” As mentioned previously, 75 of NIST's data products are currently free; i.e., have web interfaces. There is a catalog of all SRDs by number, as well as groupings by topical area. The data.nist.gov and SRD websites will be revised in the coming months to increase ease of users in browsing and locating SRDs, and to incorporate the new categories of data products described in section 4.2.

The catalog mentioned above includes the fee-based SRDs. The web pages for these SRDs will also be revised. NIST can now assign DOIs (digital object identifiers) to data products, which will increase the ability to gauge impact by citations.

\subsection{Marketing}

Each SRD has a unique community and different marketing needs. Marketing issues can be grouped into three general themes described below.

1. Improve online footprint and engage online SRD communities utilizing online marketing techniques.

a. Establish on-line marketing via Google ad-sense 
b. Cross-pollinate data products such as what is done in the Chemistry WebBook

c. Increase ease of finding SRD on the NIST website

d. Provide adequate metadata so users can understand if the product is right for them

e. Generate Wikipedia articles that can improve search engine results. (Can the Public Affairs Office create articles?)

f. Reinstate an SRD logo (the previous trademarked logo has expired)

g. Develop a gateway and repository to enable discoverability. It must be visible to Google and will require infrastructure.

h. Go where the users are (GitHub)

2. Develop use cases and other online and offline contacts to educate the public on NIST SRD.

a. Establish metrics for marketing

b. Have a presence at conferences and trade shows

c. Generate use cases and success stories, ideally in partnership with industry and other agencies

d. Collaborate with trade associations or professional societies

e. Perform pedagogical outreach, perhaps at the university level and high school level, by providing temporary full or free versions of selected SRDs for educational purposes. For this to be effective, an SRD must be integrated into coursework, which is best accomplished as a collaborative effort.

3. Generate publications about Data

a. Generate publications on best practices with data

b. Publish in the NIST Journal of Research, the Journal of Chemical and Physical Reference Data, or CODATA's Data Science Journal

\section{Recommendations}

The recommendations of the Workshop attendees are summarized below.

1. Ensure stable funding

2. Devise methods to get feedback from users

a. Consider how users would use the data, and how it could improve their lives

b. Get specific feedback on usefulness

c. Initiate a data users' consortium and/or forum

3. Metrics

a. Devise ways to better measure impact

b. Ensure staff members are trained to be aware of metrics and impact

4. Centralized technical and programming support

a. Provide a standardized infrastructure such that computers can get access to the data

b. Consider how the SRD program can better utilize "data scientists"

5. Provide dedicated website developers and IT experts

a. Enhance visibility of products

b. Assist with SRD pricing

6. Implement succession planning and life cycle planning where it is not already being done 
7. Promote marketing

a. Develop a competitive mechanism such as the NIST Innovations in Measurement Science (IMS) program 


\section{References}

[1] Kaiser DL and Hanisch RJ (2018) Technical review of NIST's free standard reference data products. NIST Special Publication 1223 14pp. https://doi.org/10.6028/NIST.SP.1223

[2] Plant AL, Locascio LE, May, WE and Gallagher PD (2014) Improved reproducibility by assuring confidence in measurements in biomedical research. Nature Methods 11: 895-898. https://doi.org/10.1038/nmeth.3076

[3] National Bureau of Standards Office of Standard Reference Data (1968) Status Report: National Standard Reference Data System. U.S. Department of Commerce, Washington, D.C., NBS Technical Note 448.

[4] Standard Reference Data Act. Public Law 90-396 [15 U.S.C. 290-290f]; 1968 Jul 11. [accessed 2018 June 11]. https://www.nist.gov/sites/default/files/documents/srd/SRDAct-2.pdf.

[5] H.R. 4284 (91 $\left.{ }^{\text {st }}\right)$ : An Act to authorize appropriations to carry out the Standard Reference Data Act. Public Law 91-131; 1969 Dec 01. [accessed 2018 June 11]. https://www.govtrack.us/congress/bills/91/hr4284/text.

[6] S. 3084-American Innovation and Competitiveness Act. Public Law 114-329, Sec. 108. Standard Reference Data Act Update; 2017 Jan 06. [accessed 2018 June 11]. https://www.congress.gov/bill/114th-congress/senate-bill/3084/text.

[7] Kramida A (2013) Critical evaluation of data on atomic energy levels, wavelengths, and transition probabilities. Fusion Science and Technology 93:313-323.

https://doi.org/10.13182/FST13-A16437 


\section{Appendix A. Workshop Agenda}

\begin{tabular}{|c|c|c|}
\hline Session Title & Presentation Title & Speaker \\
\hline History and Impact of SRD at NIST & Data Activities at NIST & Hratch Semerjian \\
\hline Current State of the SRD Program & SRD Workshop Introduction & Robert Hanisch \\
\hline \multirow{7}{*}{$\begin{array}{l}\text { SRD Enhancement/Development } \\
\text { Projects }\end{array}$} & $\begin{array}{l}\text { Revising and Updating the Digital Library of } \\
\text { Mathematical Functions }\end{array}$ & Barry Schneider \\
\hline & NISTmAb RM 8671: A New Paradigm in SRD & John Schiel \\
\hline & Laser-Induced Breakdown Spectroscopy (LIBS) & Yuri Ralchenko \\
\hline & NIST Additive Manufacturing Material Database & Yan Lu \\
\hline & Fire Model Validation Database & Randy McDermott \\
\hline & $\begin{array}{l}\text { SRD 20: X-Ray Photoelectron Spectroscopy } \\
\text { Database }\end{array}$ & John Henry Scott \\
\hline & Quantitative Optical Imaging of Biological Cells & Michael Halter \\
\hline SRD Technical Review & Technical Review of the Free SRD Collection & Debra Kaiser \\
\hline Panel Session & When Does Data Become SRD? & $\begin{array}{l}\text { Moderator: Adam Morey. Panelists: } \\
\text { Mark Madsen, Bill Wallace, Ken } \\
\text { Kroenlein, Alexander Kramida, } \\
\text { Peter Mohr, Allan Harvey, and } \\
\text { Doug White }\end{array}$ \\
\hline NIST Quality System & $\begin{array}{l}\text { The New NIST Quality System and Its Impact on } \\
\text { SRD }\end{array}$ & Sally Bruce \\
\hline
\end{tabular}




\begin{tabular}{|c|c|c|}
\hline Session Title & Presentation Title & Speaker \\
\hline Breakout Sessions & See next page for topics & $\begin{array}{l}\text { Moderators: Richard Cavanagh and } \\
\text { Barbara Guttman }\end{array}$ \\
\hline Panel Session & Managing and Funding SRDs & $\begin{array}{l}\text { Moderator: Neil Alderoty. Panelists: } \\
\text { Jim Fekete, Vicky Karen, Elisabeth } \\
\text { Mansfield, Barbara Guttman, Ron } \\
\text { Boisvert, Jerry Fraser, Terrell } \\
\text { Vanderah, Kirk Dohne, Steve Stein }\end{array}$ \\
\hline Plenary Session & $\begin{array}{l}\text { Discuss breakout results and the future of the } \\
\text { program }\end{array}$ & $\begin{array}{l}\text { Robert Hanisch, Stacy Schuur, } \\
\text { Jeanita Pritchett }\end{array}$ \\
\hline
\end{tabular}




\section{Topics for Panel Sessions and Breakout Sessions}

- When does data become SRD (Panel session)

- How would the panelists define critical evaluation?

- Pros/Cons of SRD status to a reference database and legal issues

- Alternative mechanisms to publish

- Issues associated with copyrights

- Free vs. fee based SRD

- Creation and Curation (Breakout session)

- How can we improve data gathering (internal and external sources) in an efficient manner?

- What recommendations do you have to improve the SRD program to better meet your needs?

- What does it mean to curate a data project and maintain curation overtime?

- How do you decide to begin a dataset/SRD (e.g., define a good business case, perform market research)?

- Duration (Breakout session)

- Best practices for life cycle planning

- Succession planning

- Funding (How is your work currently funded?)

- How do you know when it's time to sunset?

- Best practices for technology shifts

- Software and data file formats

- How do you measure impact of SRD?

- Best practices for dissemination, distribution, and marketing of SRD

- Managing and Funding SRDs (Panel session)

- Potential funding mechanisms

- How to get management buy-in

- How to price SRD effectively or should it be free? When should we charge for SRD? What characteristics should we think about before deciding to charge for it?

- How is SRD funded today?

- What challenges have you experienced managing/maintaining SRD?

- Do you think there is value in centrally funding SRD? 


\section{Appendix B. Workshop Registrants}

Registrants grouped by organizational unit: Engineering Laboratory (EL), Information Technology Laboratory (ITL), Material Measurement Laboratory (MML), Physical Measurement Laboratory (PML), NIST Director's Office (DO), Management Resources (MR), Laboratory Programs (LP).

\begin{tabular}{|l|l|c|}
\hline Name & Position Title & Organizational Unit \\
\hline Alejandro Miguel Campos Villacres & NIST Associate & EL \\
\hline Brian A. Weiss & Mechanical Engineer & EL \\
\hline David Goodwin & Research Chemist & EL \\
\hline Frederick M. Proctor & Group Leader & EL \\
\hline Gordon Shao & Computer Scientist & EL \\
\hline KC Morris & Group Leader & EL \\
\hline Kirk Dohne & Associate Director & EL \\
\hline Randall McDermott & Chemical Engineer & EL \\
\hline Robert Zarr & Mechanical Engineer & EL \\
\hline Simon Frechette & Mechanical Engineer & EL \\
\hline Stephen Potts & Engineer & EL \\
\hline Thomas Rollin Kramer & NIST Associate & EL \\
\hline Yan Lu & Industrial Engineer & EL \\
\hline Yung-tsun Tina Lee & Computer Scientist & EL \\
\hline Barbara Guttman & Group Leader & ITL \\
\hline Barry Schneider & Physicist & ITL \\
\hline Douglas White & Computer Scientist & ITL \\
\hline Jeffrey T. Fong & Computer Scientist & ITL \\
\hline Raghu N. Kacker & Mathematical Statistician & ITL \\
\hline Ronald Boisvert & Division Chief & ITL \\
\hline Adam Morey & Group Leader & MML \\
\hline Ala Bazyleva & Research Chemist & MML \\
\hline Alberto Marengo & Computer Engineer & MML \\
\hline Allan Harvey & Chemical Engineer & MML \\
\hline Andrei Kazakov & Physicist & MML \\
\hline Angela Lee & Physical Scientist & MML \\
\hline Arlin Stoltzfus & Biologist & MML \\
\hline Arun Moorthy & Mathematical Statistician & MML \\
\hline Ashley Beasley Green & Biologist & MML \\
\hline Benjamin Neely & Research Chemist & MML \\
\hline Bryan Calderon & NIST Associate & MML \\
\hline Cedric Powell & Scientist Emeritus & MML \\
\hline Chandler Becker & Materials Research Engineer & MML \\
\hline Chris Muzny & Physicist & MML \\
\hline Cindy McKneely & Information Specialist & MML \\
\hline Daniel W. Siderius & Chemical Engineer & \\
\hline & & \\
\hline & & \\
\hline
\end{tabular}




\begin{tabular}{|c|c|c|}
\hline Name & Position Title & Organizational Unit \\
\hline David Ross & Team Leader & MML \\
\hline David Sheen & Physicist & MML \\
\hline Debra Kaiser & Physical Scientist & MML \\
\hline Donald R. Burgess Jr. & Research Chemist & MML \\
\hline Elisabeth Mansfield & Group Leader & MML \\
\hline Eric Lemmon & Mechanical Engineer & MML \\
\hline Eric Lin & Division Chief & MML \\
\hline Erica Stein & Research Biologist & MML \\
\hline Gary Hardin & Chemical Engineer & MML \\
\hline Gary Mallard & Research Chemist & MML \\
\hline Gretchen Greene & Group Leader & MML \\
\hline Hratch Semerjian & Chief Scientist Emeritus & MML \\
\hline Ian Bell & Mechanical Engineer & MML \\
\hline James Fekete & Division Chief & MML \\
\hline Jamie Weaver & Post-Doc (NRC) & MML \\
\hline Jared Ragland & Biologist & MML \\
\hline Jeanita Pritchett & Scientific Advisor & MML \\
\hline Jessica Staymates & Research Chemist & MML \\
\hline Joe Magee & Chemical Engineer & MML \\
\hline John Henry J. Scott & Physicist & MML \\
\hline John Marino & Group Leader & MML \\
\hline John Schiel & Research Chemist & MML \\
\hline Kaleb Duelge & NIST Associate & MML \\
\hline Katherine Gettings & Biologist & MML \\
\hline Kenneth Cole & Group Leader & MML \\
\hline Kenneth Kroenlein & Group Leader & MML \\
\hline Lisa Borsuk & Biologist & MML \\
\hline Marcus Mendenhall & Physicist & MML \\
\hline Marcus Newrock & Computer Scientist & MML \\
\hline Mark McLinden & Chemical Engineer & MML \\
\hline Martin L. Green & Group Leader & MML \\
\hline Meghan Burke & Research Chemist & MML \\
\hline Michael Epstein & Research Chemist & MML \\
\hline Michael Fasolka & Deputy Director & MML \\
\hline Michael Halter & Engineer & MML \\
\hline Neil Alderoty & Executive Officer & MML \\
\hline Nicholas Ritchie & Physicist & MML \\
\hline Peter Linstrom & Chemical Engineer & MML \\
\hline Raymond Plante & Physicist & MML \\
\hline Rebecca Kraft & Geologist & MML \\
\hline Regina Easley & Research Chemist & MML \\
\hline Robert Goldberg & Scientist Emeritus & MML \\
\hline Robert Hanisch & Director, ODI & MML \\
\hline
\end{tabular}




\begin{tabular}{|c|c|c|}
\hline Name & Position Title & Organizational Unit \\
\hline Robert Watters & NIST Associate & MML \\
\hline Russell D Johnson III & Research Chemist & MML \\
\hline Sam Forry & Biologist & MML \\
\hline Sherena Johnson & Information Specialist & MML \\
\hline Stacy Schuur & Scientific Advisor & MML \\
\hline Steve Stein & NIST Fellow & MML \\
\hline T. N. Bhat & Research Chemist & MML \\
\hline Tamae Wong & Research Chemist & MML \\
\hline Terrell Vanderah & NIST Associate & MML \\
\hline Torey Liepa & Information Specialist & MML \\
\hline Tytus Mak & Research Chemist & MML \\
\hline Ursula Kattner & Physical Scientist & MML \\
\hline Vicky Lynn Karen & Research Chemist & MML \\
\hline Virgil Provenzano & NIST Associate & MML \\
\hline Vladimir Diky & Chemical Engineer & MML \\
\hline Vladimir Orkin & Biologist & MML \\
\hline William E. Wallace & Group Leader & MML \\
\hline Xiang Li & NIST Associate & MML \\
\hline Alexander Kramida & Physicist & PML \\
\hline Bryan Barnes & Physicist & PML \\
\hline Csilla Szabo-Foster & NIST Associate & PML \\
\hline Edward Saloman & NIST Associate & PML \\
\hline Gerald Fraser & Division Chief & PML \\
\hline Gillian Nave & Physicist & PML \\
\hline Haris Kunari & NIST Associate & PML \\
\hline Jonathan Hardis & Scientific Advisor & PML \\
\hline Joseph Fowler & Physicist & PML \\
\hline Joseph Reader & Scientist Emeritus & PML \\
\hline Joseph Tan & Physicist & PML \\
\hline Karen Olsen & Computer Scientist & PML \\
\hline Kimberly Briggman & Group Leader & PML \\
\hline Mark Tyra & Physical Scientist & PML \\
\hline Paul Bergstrom & Physicist & PML \\
\hline Peter Mohr & Group Leader & PML \\
\hline Stephen M. Seltzer & NIST Associate & PML \\
\hline Yuri Ralchenko & Group Leader & PML \\
\hline Mark Madsen & Attorney & DO \\
\hline Andrea Medina-Smith & Metadata Librarian & MR \\
\hline Briget Wynne & Research Librarian & MR \\
\hline Kimberly A. Tryka & Research Data Librarian & MR \\
\hline Regina Avila & Digital Services Librarian & MR \\
\hline Stacy Bruss & Research Librarian & MR \\
\hline
\end{tabular}




\begin{tabular}{|l|l|c|}
\hline Name & Position Title & Organizational Unit \\
\hline Sally Bruce & NIST Quality Manager & LP \\
\hline Richard Cavanagh & Director, SPO & LP \\
\hline
\end{tabular}


Appendix A. Workshop Agenda

\begin{tabular}{|c|c|c|}
\hline Session Title & Presentation Title & Speaker \\
\hline History and Impact of SRD at NIST & Data Activities at NIST & Hratch Semerjian \\
\hline Current State of the SRD Program & SRD Workshop Introduction & Robert Hanisch \\
\hline \multirow{7}{*}{$\begin{array}{l}\text { SRD Enhancement/Development } \\
\text { Projects }\end{array}$} & $\begin{array}{l}\text { Revising and Updating the Digital Library of } \\
\text { Mathematical Functions }\end{array}$ & Barry Schneider \\
\hline & NISTmAb RM 8671: A New Paradigm in SRD & John Schiel \\
\hline & Laser-Induced Breakdown Spectroscopy (LIBS) & Yuri Ralchenko \\
\hline & NIST Additive Manufacturing Material Database & Yan Lu \\
\hline & Fire Model Validation Database & Randy McDermott \\
\hline & $\begin{array}{c}\text { SRD 20: X-Ray Photoelectron Spectroscopy } \\
\text { Database }\end{array}$ & John Henry Scott \\
\hline & Quantitative Optical Imaging of Biological Cells & Michael Halter \\
\hline SRD Technical Review & Technical Review of the Free SRD Collection & Debra Kaiser \\
\hline Panel Session & When Does Data Become SRD? & $\begin{array}{l}\text { Moderator: Adam Morey. Panelists: } \\
\text { Mark Madsen, Bill Wallace, Ken } \\
\text { Kroenlein, Alexander Kramida, } \\
\text { Peter Mohr, Allan Harvey, and } \\
\text { Doug White }\end{array}$ \\
\hline NIST Quality System & $\begin{array}{l}\text { The New NIST Quality System and Its Impact on } \\
\text { SRD }\end{array}$ & Sally Bruce \\
\hline
\end{tabular}




\begin{tabular}{|c|c|c|}
\hline Session Title & Presentation Title & Speaker \\
\hline Breakout Sessions & See next page for topics & $\begin{array}{l}\text { Moderators: Richard Cavanagh and } \\
\text { Barbara Guttman }\end{array}$ \\
\hline Panel Session & Managing and Funding SRDs & $\begin{array}{l}\text { Moderator: Neil Alderoty. Panelists: } \\
\text { Jim Fekete, Vicky Karen, Elisabeth } \\
\text { Mansfield, Barbara Guttman, Ron } \\
\text { Boisvert, Jerry Fraser, Terrell } \\
\text { Vanderah, Kirk Dohne, Steve Stein }\end{array}$ \\
\hline Plenary Session & $\begin{array}{l}\text { Discuss breakout results and the future of the } \\
\text { program }\end{array}$ & $\begin{array}{l}\text { Robert Hanisch, Stacy Schuur, } \\
\text { Jeanita Pritchett }\end{array}$ \\
\hline
\end{tabular}




\section{Topics for Panel Sessions and Breakout Sessions}

- When does data become SRD (Panel session)

- How would the panelists define critical evaluation?

- Pros/Cons of SRD status to a reference database and legal issues

- Alternative mechanisms to publish

- Issues associated with copyrights

- Free vs. fee based SRD

- Creation and Curation (Breakout session)

- How can we improve data gathering (internal and external sources) in an efficient manner?

- What recommendations do you have to improve the SRD program to better meet your needs?

- What does it mean to curate a data project and maintain curation overtime?

- How do you decide to begin a dataset/SRD (e.g., define a good business case, perform market research)?

- Duration (Breakout session)

- Best practices for life cycle planning

- Succession planning

- Funding (How do you currently fund your work?)

- How do you know when it's time to sunset?

- Best practices for technology shifts

- Software and data file formats

- How do you measure impact of SRD?

- Best practices for dissemination, distribution, and marketing of an SRD

- Managing and Funding SRDs (Panel session)

- Potential funding mechanisms

- How to get management buy-in

- How to price an SRD effectively or should it be free? When should we charge for SRD? What characteristics should we think about before deciding to charge for it?

- How is SRD funded today?

- What challenges have you experienced managing/maintaining an SRD?

- Do you think there is value in continuing to do centrally funded SRD? 


\section{Appendix B. Workshop Registrants}

Registrants grouped by organizational unit: Engineering Laboratory (EL), Information Technology Laboratory (ITL), Material Measurement Laboratory (MML), Physical Measurement Laboratory (PML), NIST Director's Office (DO), Management Resources (MR), Laboratory Programs (LP).

\begin{tabular}{|l|l|c|}
\hline Name & Position Title & Organizational Unit \\
\hline Alejandro Miguel Campos Villacres & NIST Associate & EL \\
\hline Brian A. Weiss & Mechanical Engineer & EL \\
\hline David Goodwin & Research Chemist & EL \\
\hline Frederick M. Proctor & Group Leader & EL \\
\hline Gordon Shao & Computer Scientist & EL \\
\hline KC Morris & Group Leader & EL \\
\hline Kirk Dohne & Associate Director & EL \\
\hline Randall McDermott & Chemical Engineer & EL \\
\hline Robert Zarr & Mechanical Engineer & EL \\
\hline Simon Frechette & Mechanical Engineer & EL \\
\hline Stephen Potts & Engineer & EL \\
\hline Thomas Rollin Kramer & NIST Associate & EL \\
\hline Yan Lu & Industry Engineer & EL \\
\hline Yung-tsun Tina Lee & Computer Scientist & EL \\
\hline Barbara Guttman & Group Leader & ITL \\
\hline Barry Schneider & Physicist & ITL \\
\hline Douglas White & Computer Scientist & ITL \\
\hline Jeffrey T. Fong & Computer Scientist & ITL \\
\hline Raghu N. Kacker & Mathematical Statistician & ITL \\
\hline Ronald Boisvert & Division Chief & ITL \\
\hline Adam Morey & Group Leader & MML \\
\hline Ala Bazyleva & Research Chemist & MML \\
\hline Alberto Marengo & Computer Engineer & MML \\
\hline Allan Harvey & Chemical Engineer & MML \\
\hline Andrei Kazakov & Physicist & MML \\
\hline Angela Lee & Physical Scientist & MML \\
\hline Arlin Stoltzfus & Biologist & MML \\
\hline Arun Moorthy & Mathematical Statistician & MML \\
\hline Ashley Beasley Green & Biologist & MML \\
\hline Benjamin Neely & Research Chemist & MML \\
\hline Bryan Calderon & NIST Associate & MML \\
\hline Cedric Powell & Scientist Emeritus & MML \\
\hline Chandler Becker & Materials Research Engineer & MML \\
\hline Chris Muzny & Physicist & MML \\
\hline Cindy McKneely & Information Specialist & MML \\
\hline Daniel W. Siderius & Chemical Engineer & \\
\hline & & \\
\hline & & \\
\hline
\end{tabular}




\begin{tabular}{|c|c|c|}
\hline Name & Position Title & Organizational Unit \\
\hline David Ross & Team Leader & MML \\
\hline David Sheen & Physicist & MML \\
\hline Debra Kaiser & Physical Scientist & MML \\
\hline Donald R. Burgess Jr. & Research Chemist & MML \\
\hline Elisabeth Mansfield & Group Leader & MML \\
\hline Eric Lemmon & Mechanical Engineer & MML \\
\hline Eric Lin & Division Chief & MML \\
\hline Erica Stein & Research Biologist & MML \\
\hline Gary Hardin & Chemical Engineer & MML \\
\hline Gary Mallard & Research Chemist & MML \\
\hline Gretchen Greene & Group Leader & MML \\
\hline Hratch Semerjian & NIST Emeritus & MML \\
\hline Ian Bell & Mechanical Engineer & MML \\
\hline James Fekete & Division Chief & MML \\
\hline Jamie Weaver & Post-Doc (NRC) & MML \\
\hline Jared Ragland & Biologist & MML \\
\hline Jeanita Pritchett & Scientific Advisor & MML \\
\hline Jessica Staymates & Research Chemist & MML \\
\hline Joe Magee & Chemical Engineer & MML \\
\hline John Henry J. Scott & Physicist & MML \\
\hline John Marino & Group Leader & MML \\
\hline John Schiel & Research Chemist & MML \\
\hline Kaleb Duelge & NIST Associate & MML \\
\hline Katherine Gettings & Biologist & MML \\
\hline Kenneth Cole & Group Leader & MML \\
\hline Kenneth Kroenlein & Group Leader & MML \\
\hline Lisa Borsuk & Research Scientist & MML \\
\hline Marcus Mendenhall & Physicist & MML \\
\hline Marcus Newrock & Computer Scientist & MML \\
\hline Mark McLinden & Chemical Engineer & MML \\
\hline Martin L. Green & Group Leader & MML \\
\hline Meghan Burke & Research Chemist & MML \\
\hline Michael Epstein & Research Chemist & MML \\
\hline Michael Fasolka & Deputy Director & MML \\
\hline Michael Halter & Engineer & MML \\
\hline Neil Alderoty & Executive Officer & MML \\
\hline Nicholas Ritchie & Physicist & MML \\
\hline Peter Linstrom & Chemical Engineer & MML \\
\hline Raymond Plante & Physicist & MML \\
\hline Rebecca Kraft & Geologist & MML \\
\hline Regina Easley & Research Chemist & MML \\
\hline Robert Goldberg & Scientist Emeritus & MML \\
\hline Robert Hanisch & Director, ODI & MML \\
\hline
\end{tabular}




\begin{tabular}{|c|c|c|}
\hline Name & Position Title & Organizational Unit \\
\hline Robert Watters & NIST Associate & MML \\
\hline Russell D Johnson III & Research Chemist & MML \\
\hline Sam Forry & Biologist & MML \\
\hline Sherena Johnson & Information Specialist & MML \\
\hline Stacy Schuur & Scientific Advisor & MML \\
\hline Steve Stein & NIST Fellow & MML \\
\hline T. N. Bhat & Research Chemist & MML \\
\hline Tamae Wong & Research Chemist & MML \\
\hline Terrell Vanderah & NIST Associate & MML \\
\hline Torey Liepa & Information Specialist & MML \\
\hline Tytus Mak & Research Chemist & MML \\
\hline Ursula Kattner & Physical Scientist & MML \\
\hline Vicky Lynn Karen & Research Chemist & MML \\
\hline Virgil Provenzano & NIST Associate & MML \\
\hline Vladimir Diky & Chemical Engineer & MML \\
\hline Vladimir Orkin & Biologist & MML \\
\hline William E. Wallace & Group Leader & MML \\
\hline Xiang Li & NIST Associate & MML \\
\hline Alexander Kramida & Physicist & PML \\
\hline Bryan Barnes & Physicist & PML \\
\hline Csilla Szabo-Foster & NIST Associate & PML \\
\hline Edward Saloman & NIST Associate & PML \\
\hline Gerald Fraser & Division Chief & PML \\
\hline Gillian Nave & Physicist & PML \\
\hline Haris Kunari & NIST Associate & PML \\
\hline Jonathan Hardis & Scientific Advisor & PML \\
\hline Joseph Fowler & Physicist & PML \\
\hline Joseph Reader & Scientist Emeritus & PML \\
\hline Joseph Tan & Physicist & PML \\
\hline Karen Olsen & Computer Scientist & PML \\
\hline Kimberly Briggman & Group Leader & PML \\
\hline Mark Tyra & Physical Scientist & PML \\
\hline Paul Bergstrom & Physicist & PML \\
\hline Peter Mohr & Group Leader & PML \\
\hline Stephen M. Seltzer & NIST Associate & PML \\
\hline Yuri Ralchenko & Group Leader & PML \\
\hline Mark Madsen & Attorney & DO \\
\hline Andrea Medina-Smith & Metadata Librarian & MR \\
\hline Briget Wynne & Research Librarian & MR \\
\hline Kimberly A. Tryka & Research Data Librarian & MR \\
\hline Regina Avila & Digital Services Librarian & MR \\
\hline Stacy Bruss & Research Librarian & MR \\
\hline
\end{tabular}




\begin{tabular}{|l|l|c|}
\hline Name & Position Title & Organizational Unit \\
\hline Sally Bruce & NIST Quality Manager & LP \\
\hline Richard Cavanagh & Director, SPO & LP \\
\hline
\end{tabular}

